\title{
Experimental determination of cold water temperature at the inlet to solar water storage tanks
}

\author{
Miroslaw Zukowski ${ }^{1, *}$ \\ ${ }^{1}$ Bialystok University of Technology, Department of HVAC Engineering, ul. Wiejska 45E, \\ 15-351 Białystok, Poland
}

\begin{abstract}
In the present work, results of experimental research on the mains water temperature supplying the Solar Domestic Hot Water system in the period from 2016 to 2018 are shown. The test object is located in the Hotel for Research Assistants on Bialystok University of Technology campus in Poland. One of the elements that will guarantee the correct energy balance of a hot tap-water system is the exact determination of the cold water temperature. The aim of this study is estimation of the temperature of the mains water flowing into the district heating substation and the water feeding directly the heat storage tanks. The research results showed that the average value of the cold water was $14.09^{\circ} \mathrm{C}$ during the 3 years of measurements. Moreover, it was shown that this temperature increased by about $0.4^{\circ} \mathrm{C}$ as a result of heat exchange with the air inside the substation. In the article, the author proposed modifications of coefficients in a commonly used model developed by National Renewable Energy Laboratory for determining the temperature of mains water in energy simulations. The proposed changes allow for accurate modelling of the cold water temperature under the climate conditions of north-eastern Poland.
\end{abstract}

\section{Introduction}

The temperature of mains water $T_{M}$ depends primarily on its initial temperature in the treatment station, the ground temperature, and the flow time to the end user. Due to the fact that the ground temperature is not widely studied, the dependences of cold water temperature on the outside air temperature have been developed. It is necessary to determine the exact value of the cold water temperature in the case of economic analysis and energy simulations of Solar Water Heating Systems (SWHS). A thorough review and comparison of different methods of determining this parameter has been done by Chmielewska [1]. This paper discusses models developed by National Renewable Energy Laboratory (NERL), recommended by California Energy Commission [2], and included in Task 44 implemented by International Energy Agency [3]. The analysis that has been carried out in this work [1] proved quite a large discrepancy between the results of calculations and measurements.

\footnotetext{
* Corresponding author: m.zukowski@ pb.edu.pl
} 


\section{Description of the method for estimating the mains water temperature}

The method to determine the mains water temperature $T_{M}$, recommended by NERL, has been considered in the current article. The reason for choosing this method has been that the relation (Eq. 1) developed by Hendron et al. [4] and Burch \& Christensen [5] is used in many energy simulation programs. A good example would be EnergyPlus - the input object named Site: WaterMainsTemperature [6]. It should be noted that the temperature values must be taken in the Fahrenheit scale in this equation:

$$
T_{M}=T_{A-a v g}+T_{O F F S E T}+\operatorname{Ratio} \cdot\left(\frac{T_{A-\max }-T_{A-\min }}{2}\right) \sin \left[\frac{360}{365} \cdot(\text { day\# }-15-\mathrm{Lag})-90\right],
$$

where:

$T_{A \text {-avg }}$ - annual average ambient air temperature $\left({ }^{\circ} \mathrm{F}\right)$;

$T_{A-\max }-$ maximum monthly average ambient temperature $\left({ }^{\circ} \mathrm{F}\right)$;

$T_{A-\min }-$ minimum monthly average ambient temperature $\left({ }^{\circ} \mathrm{F}\right)$;

Ratio $=0.4+0.01 \cdot\left(T_{A-a v g}-T_{A-n o m}\right)$

day\# = Julian day from 1 to 365 ;

Lag $=35-\left(T_{\text {A-avg }}-T_{\text {A-nom }}\right)$.

In the above relationship there are three variables: $T_{\text {OFFSET, Ratio, and Lag, which depend }}$ on specific climate features, soil parameters, and burial depths of water pipes. It should be mentioned, that Eq. (1) has been developed in relation to nominal temperature $T_{A-n o m}=6.67^{\circ} \mathrm{C}$ $\left(44^{\circ} \mathrm{F}\right)$, and $T_{\text {OFFSET }}=-14.44^{\circ} \mathrm{C}\left(6^{\circ} \mathrm{F}\right)$. We can find a suggestion to reduce $T_{O F F S E T}$ value to $-15^{\circ} \mathrm{C}\left(5^{\circ} \mathrm{F}\right)$ in Burch and Thornton conference paper [7]. Another assumption was to set a minimum temperature on January 15 , i.e. day\# $=15$. To calculate the average monthly temperature of the mains water, the following relationship should be used [8]:

$$
\text { day\# }=30 \cdot \text { month\# }-15 \text {. }
$$

The aim of this work is to verify the accuracy of calculations using Eq. 1 under the conditions of the climate of north-eastern Poland.

\section{Validation of the method based on the measurements}

The measurement results come from the domestic hot water (DHW) system supported by solar collectors, which is located in the Hotel for Research Assistants on Bialystok University of Technology (BUT) campus (Poland). The measuring system was made as part of Regional Operational Program of Podlaskie Voivodeship - "Study of the effectiveness of active and passive methods to improve the energy efficiency of BUT infrastructure supported by renewable energy sources". Detailed information about the project and research object are given by Zukowski in $[9,10]$.

The system under consideration consists of 35 flat plate collectors with a total area of $72 \mathrm{~m}^{2}, 21$ evacuated tube collectors with a total area of $74 \mathrm{~m}^{2}$, and 8 tanks (Fig. 1) - each with the capacity of $1 \mathrm{~m}^{3}$.

For the purposes of this work the cold water temperature was measured at 9 points using PT500 platinum resistance temperature sensors (Fig. 1). The location of the measurement points (marked with a dotted line) is shown in Fig. 2. There are two identical Solar Domestic Hot Water (SDHW) systems connected in parallel for each set of solar collectors. 


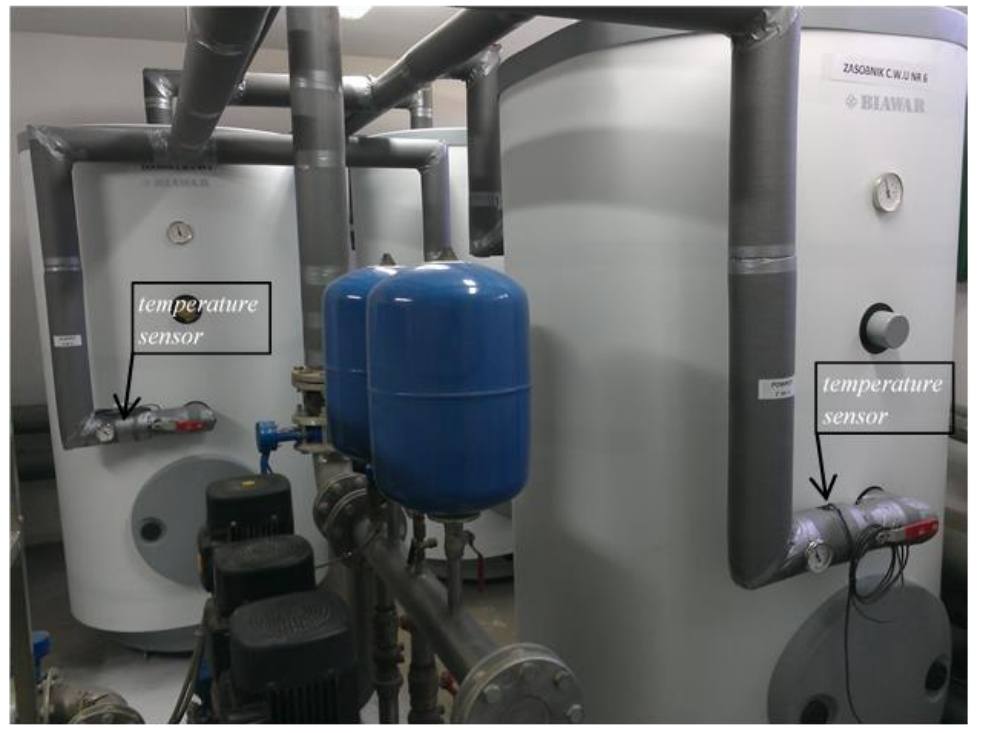

Fig. 1. Water heat storage tanks and selected temperature sensors.

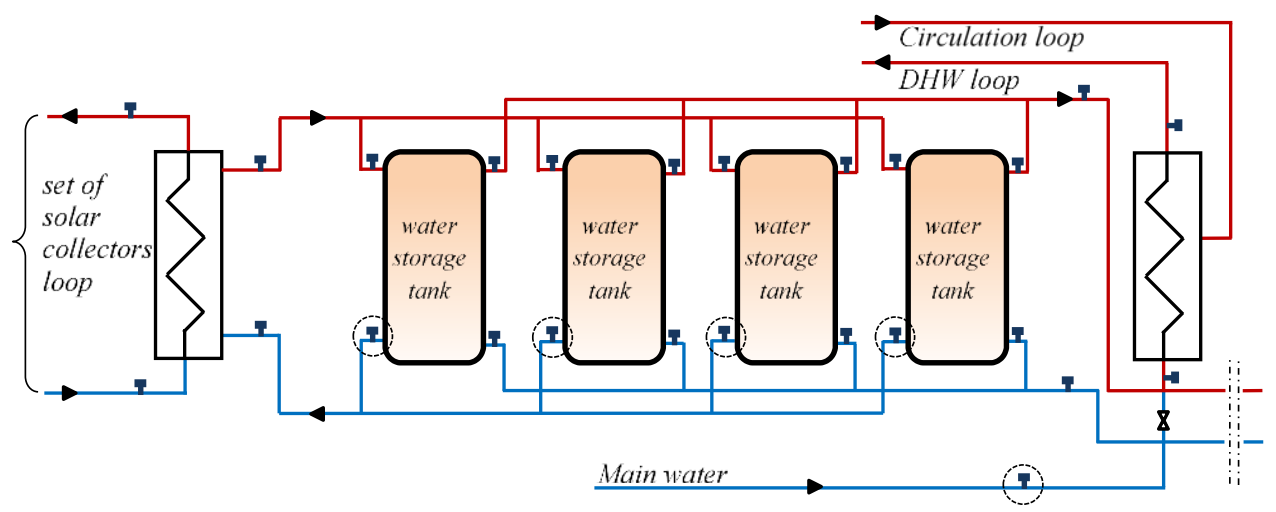

Fig. 2. Simplified hydraulic diagram of the DHW system.

SDHW system is equipped with automatic data collection (ADC) system. One of the screen views presenting monitored performance is shown in Fig. 3. Temperature and other operating elements are measured every 1 minute. The basic parameters of ambient air are registered at a higher sampling frequency (every 5 seconds) by the weather station located on the roof of the hotel. All measurement results used in this work have been averaged at monthly intervals.

Fig. 4 presents the temperature of the outside air that was measured during the relevant period, i.e. from January 2016 to December 2018. However, average annual, maximum and minimum monthly values are given in Table 1 . Additionally, besides the measured temperature, are given its value (Table 1) for a typical meteorological year (TMY) for Bialystok POL_Bialystok.122950_IMGW. 


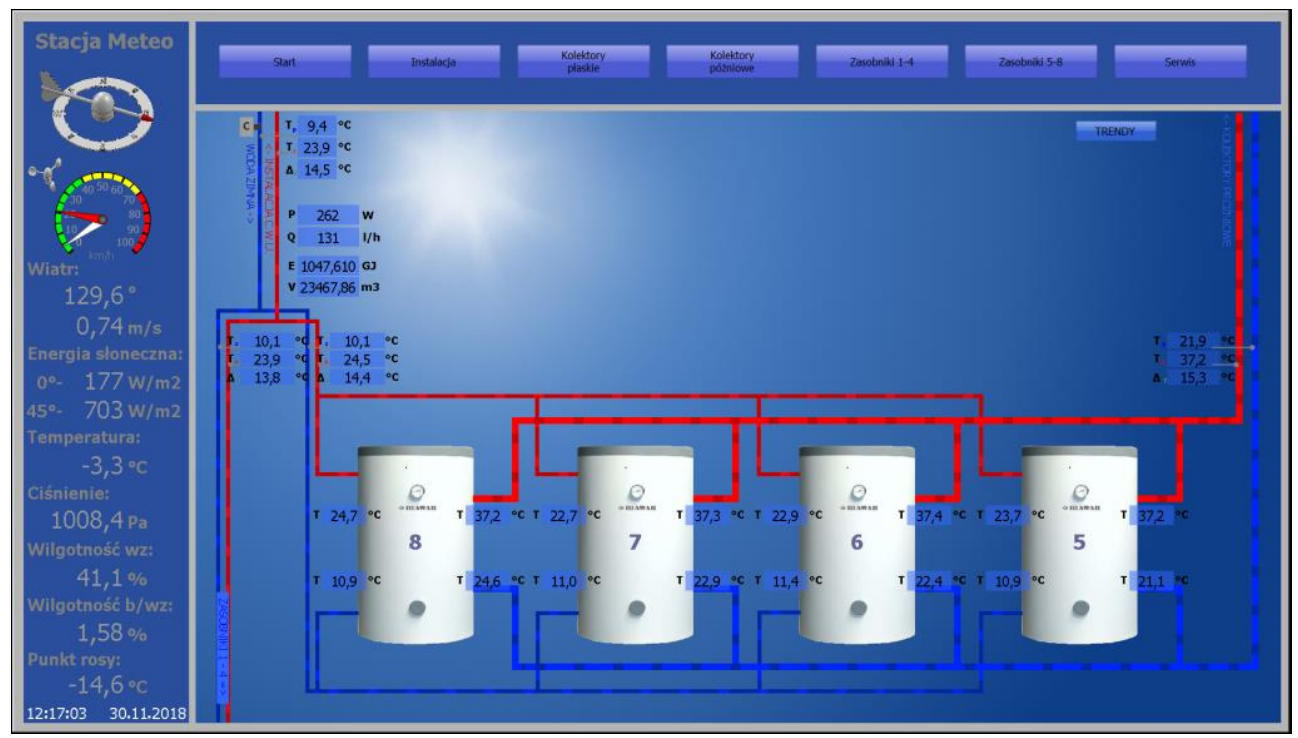

Fig. 3. Screenshot of the monitoring system for the storage tanks from 5 to 8.

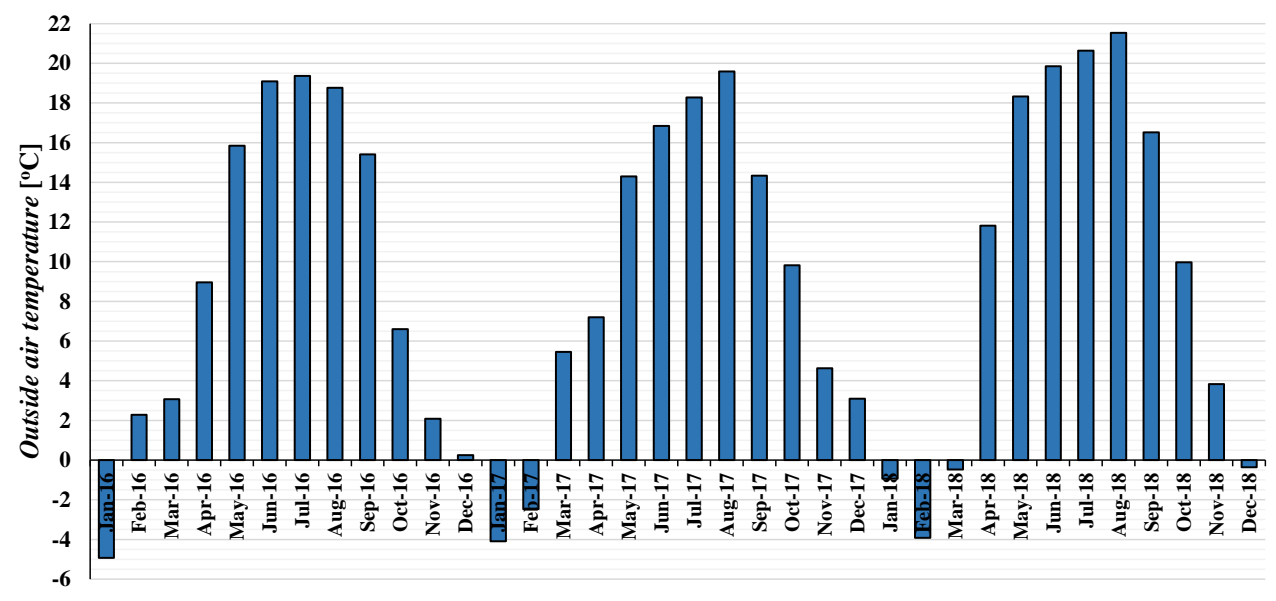

Fig. 4. Average monthly outside air temperature measured in 2016-2018.

Table 1. The monthly average temperature of the outside air in 2016-2018.

\begin{tabular}{|c|c|c|c|c|}
\hline & $\boldsymbol{T}_{\text {A-max }}\left({ }^{\circ} \mathbf{C}\right)$ & $\boldsymbol{T}_{\text {A-min }}\left({ }^{\circ} \mathbf{C}\right)$ & $\boldsymbol{T}_{\text {A-avg }}\left({ }^{\circ} \mathbf{C}\right)$ & $\boldsymbol{T}_{\text {A-avg- }} \boldsymbol{T}_{\text {A-TMY }}\left({ }^{\circ} \mathbf{C}\right)$ \\
\hline 2016 & 19.36 & -4.93 & 8.90 & 2.02 \\
\hline 2017 & 19.59 & -4.10 & 8.91 & 2.04 \\
\hline 2018 & 21.53 & -3.92 & 9.73 & 2.86 \\
\hline $\mathrm{TMY}$ & 17.27 & -4.90 & 6.87 & \\
\hline
\end{tabular}

The next three graphs show the comparison of the results of cold water temperature measurements with the results of calculations (Eq. 1) made in two cases. In the first version the standard coefficients suggested by Burch and Christensen [5] have been used, while the parameters corrected by the author have been applied in the second variant of calculations. 


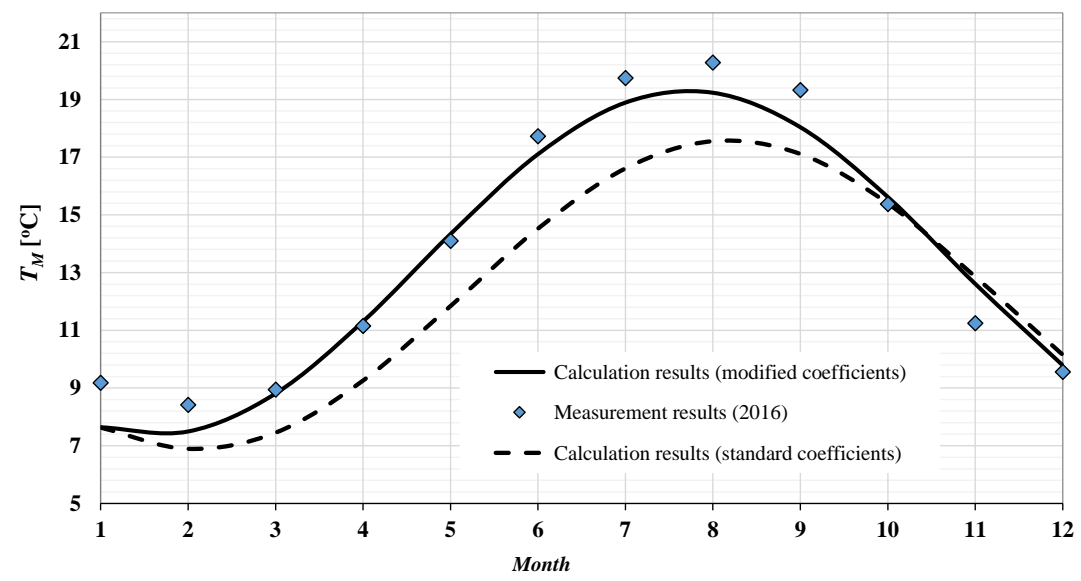

Fig. 5. The cold water temperature change in 2016.

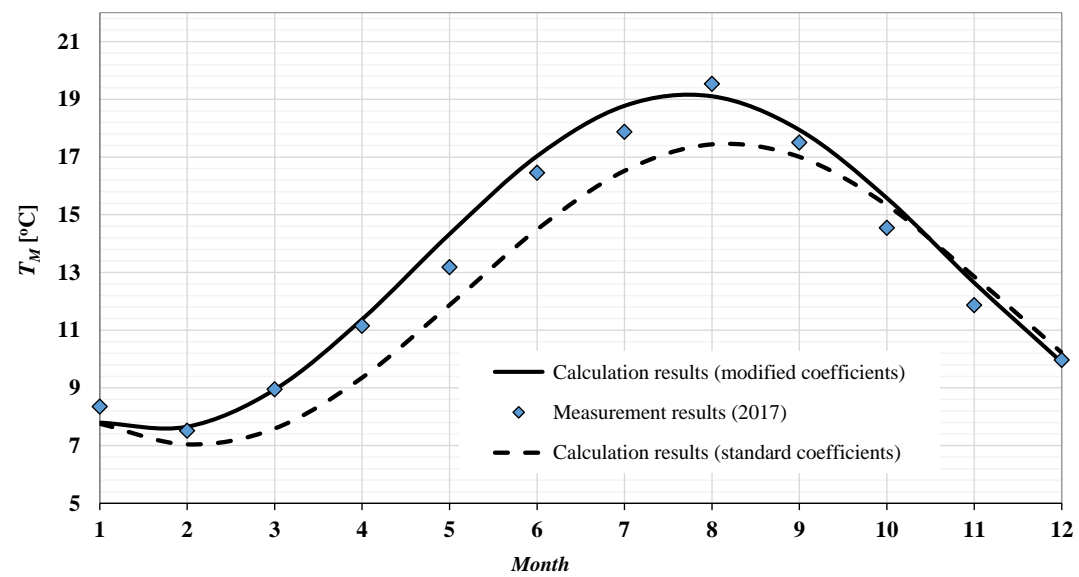

Fig. 6. The cold water temperature change in 2017.

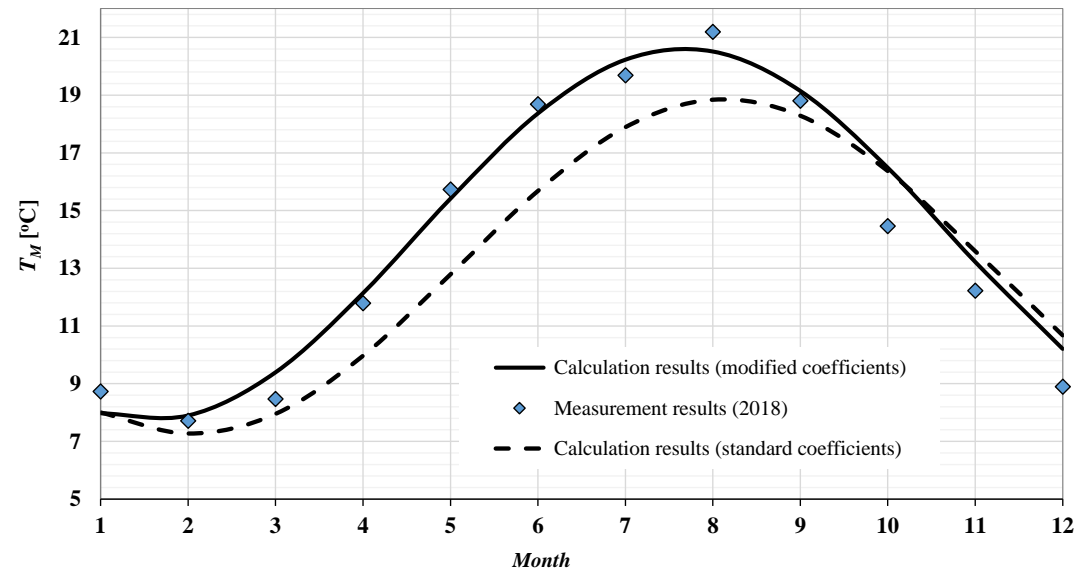

Fig. 7. The cold water temperature change in 2018. 
The new and, for comparison, the standard values of selected coefficients from Eq. 1 are listed in Table 2. As we can notice on Figs. 5-7, the proposed correction of constants by the author allowed for a fairly accurate adjustment of simulation results to the measurements. The following relationship (Eq. 3) has been used in order to estimate the level of their compatibility:

$$
R M S E=\sqrt{\sum_{i=1}^{n}\left(T_{M-m}-T_{M-c a l}\right)^{2} / n}
$$

where:

$T_{M-m}$ - temperature value derived from the measurements $\left({ }^{\circ} \mathrm{C}\right)$;

$T_{M \text {-cal }}$ - temperature value calculated from the Eq. $1\left({ }^{\circ} \mathrm{C}\right)$;

$n$ - number of months.

In the case when the standard model has been applied, the RMSE value is 1.72 , and when new values of coefficients have been used, we can obtain higher level of precision because RMSE equals 0.799 .

Table 2. Selected coefficients of Eq. 1 - standard and modified by the author.

\begin{tabular}{|c|c|c|}
\hline & Standard & Modified \\
\hline A day with a minimum ambient temperature & $15^{\text {th }}$ January & $1^{\text {th }}$ January \\
\hline$T_{\text {OFFSET }}$ & $-14.44^{\circ} \mathrm{C}\left(6^{\circ} \mathrm{F}\right)$ & $-13.33^{\circ} \mathrm{C}\left(8^{\circ} \mathrm{F}\right)$ \\
\hline Coefficient in the Ratio & 0.4 & 0.45 \\
\hline
\end{tabular}

\section{The temperature of the water supplying solar hot water storage tanks}

Mains water that flows into a district heating substation heats up as a result of contact with warm internal air. Of course, this is a useful case because the amount of energy needed to produce DHW is reduced. Fig. 8 shows the difference of the water temperature at the inlet to the storage tanks $T_{S T \text {-avg }}$ and at the inlet to the substation $T_{M}$. The value of $T_{S T \text {-avg }}$ has been calculated as an average of 8 values (Fig. 2) corresponding to each of the storage tanks.

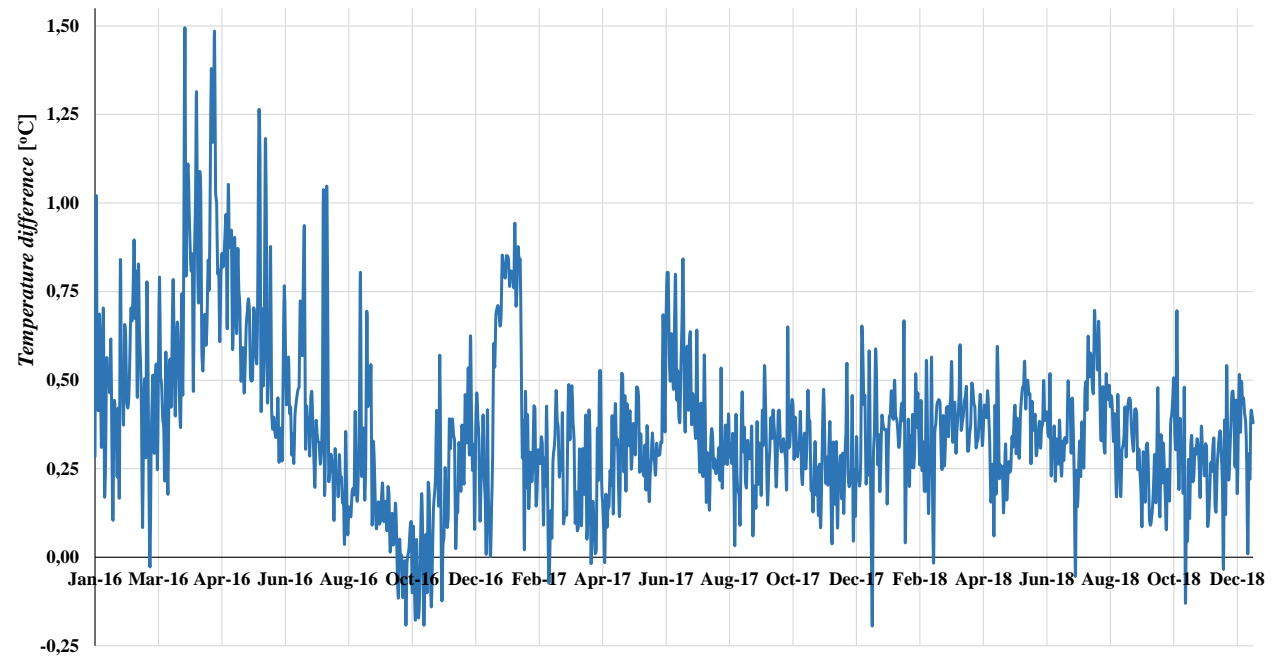

Fig. 8. Change in the temperature difference between $T_{S T-a v g}$ and $T_{M}$ in the years 2016-2018. 
As can be seen in Fig. 8, only in the short period from October 13 to November 15, 2016 the mains water temperature was higher than the air temperature inside the substation. The temperature difference between $T_{S T-a v g}$ and $T_{M}$ was $0.43^{\circ} \mathrm{C}$ in 2016 , and the same value $0.34^{\circ} \mathrm{C}$ was in 2017 and 2018. Thus, the average value was 0.37 in the period of 3 years of measurements. This is a rather low value because the water pipes were insulated with PE foam coatings with a thickness of $30 \mathrm{~mm}$.

\section{Conclusion}

In the current work, the mains water temperature supplying the SDHW system, located in the Hotel for Research Assistants on BUT campus, has been determined. The average value of $T_{M}$ was $14.12^{\circ} \mathrm{C}$ during the 3 years of measurements from 2016 to 2018 . In addition, it turned out that the cold water was heated by about $0.4^{\circ} \mathrm{C}$ on average, flowing through the substation. The Polish guidelines [11] for determining the cold water temperature recommend taking the value of $10^{\circ} \mathrm{C}$. As shown by the measurement results, this is too low value. However, it should be noted, that the average temperature of the outside air was $2.31^{\circ} \mathrm{C}$ higher than the value for a typical meteorological year.

Another element of the novelty is to propose new coefficients (Table 2) to the Hendron et al. model [4]. This modification allows for accurate modeling of the mains water temperature under the climate conditions of north-eastern Poland.

This work was performed within the framework of Grant of the Bialystok University of Technology and financed by the Ministry of Science and Higher Education of the Republic of Poland.

\section{References}

1. A. Chmielewska, E3S Web of Conferences 44, 00017 (2018)

2. T. Ferris, L. Froess, D. A. Ross, Residential Alternative Calculation Method Reference Manual (California Energy Commission Staff Report, 2016)

3. Task 44HPP Annex 38, The Reference Framework for System Simulations of the IEA SHC, Technical Report C1 Part A (2013)

4. R. Hendron, R. Anderson, C. Christensen, M. Eastment, P. Reeves, SIMBUILD2004 Conference, Colorado, 1-11 (2004)

5. J. Burch, C. Christensen, Solar 2007 Conference, Cleveland, Ohio (2007)

6. EnergyPlus ${ }^{\mathrm{TM}}$, Documentation - Engineering Reference Version 8.8.0, U.S. Department of Energy (2018)

7. J. Burch, J. Thornton, World Renewable Energy Forum Denver, Colorado (2012)

8. R. Hendron, Building America Research Benchmark Definition, Technical Report NREL/TP-550-42662 (2008)

9. M. Zukowski, Advances in Renewable Energy Research (CRC Press/Taylor \& Francis, 33-44, 2017)

10. M. Zukowski, E3S Web of Conferences 22, 00209 (2017)

11. Regulation of the Minister of Infrastructure and Development on the methodology for determining the energy performance of a building or part of a building and energy performance certificates (2015) 